\title{
Health facilitation in primary care
}

Woody Caan and John Lutchmiah APU Anglia Institute of Health and Social Care, Chelmsford, Essex, UK, Karen Thomson Homerton School of Health Studies, Cambridge, UK and Jill Toocaram APU Anglia Institute of Health and Social Care, Chelmsford, Essex, UK

\begin{abstract}
This is a preliminary report on a quality improvement project for people with learning disabilities (PWLD) in one London Borough. The strategy document Valuing people required the implementation of a specific activity at two levels: both organizational development and individual health action plans. This activity was called health facilitation. It was left to local services to introduce health facilitation either by extension of existing roles or by creation of new specialist posts. Using neighbourhood renewal funding to improve access to health services, Barking and Dagenham chose to create new posts. This paper will focus on just one of these innovative posts, linked to improving transition planning for school leavers with learning disabilities. There was a pressing local need to improve continuity of care between child and adult services. Multiple methods were used to investigate this new Health Facilitator (HF) role. The HF carried out both service development and person-toperson work, with a wide variety of contacts. Developing 'signposting' and appropriate referral systems for young people led to improved access to adult services. In general, this developmental role was seen as making a positive contribution in addressing the gaps in current services for young PWLD. The findings of this evaluation have already led to changes within local services and shaped future workforce planning.
\end{abstract}

Key words: health facilitator; learning disabilities; primary health care; partnership for evaluation

\section{Background}

\section{Opportunities from neighbourhood renewal}

Improving health and reducing inequality is a strategic aim of the Neighbourhood Renewal Fund (NRF: Social Exclusion Unit, 2001). Support from the NRF in 2003-2004 enabled Barking and Dagenham to implement and evaluate innovative Health Facilitator (HF) posts for people with learning disabilities (PWLD). In line with the national strategy of the NRF, improving health would involve 'better access to services' for PWLD.

\section{The implementation of valuing people}

PWLD have greater unrecognized and unmet health needs than the general population (Matthews et al., 2002). The Disability Rights Commission has

Address for correspondence: G.J. Lutchmiah, APU, Chelmsford, Essex CM1 1SQ, UK. Email: g.j.lutchmiah@apu.ac.uk confirmed the drastic effect of this health inequality on life expectancy (Trueland, 2004). To improve the health of this disadvantaged population, access to both primary health care and specialist secondary care is crucial:

There is overwhelming evidence that a significant proportion of health needs are unrecognised and untreated. The many barriers to health care experienced by people with learning disabilities contribute to this high level of unmet health needs.

(NHS Health Scotland, 2004)

Recently the National Patient Safety Agency (NPSA, 2004) confirmed that 'illness or disease being mis- or under-diagnosed' is a key risk area for PWLD.

\section{Young people in transition}

The Valuing people strategy (DH, 2001a) had identified a need to improve continuity of services 
for young PWLD as they move into adulthood. In relation to better access to health services this 'was proving difficult to meet' (Commission for Social Care Inspection, 2004). When the Nursing Advisor for the Department of Health was asked to name one key issue for learning disabilities, she selected improving access to health care services (McMillan, 2004). New Information Technology to support transition (SCIE, 2003) has not replaced the need for human expertise in the transition process. The children's National service framework (DH, 2004a) has highlighted the need for better evidence about effective transition planning. In particular 'the evidence now required can only be generated from evaluative research of practice and models of service delivery' (Beresford, 2004). A number of small-scale initiatives have sought to improve transitions for individual school leavers (e.g., seven people: Cameron and Murphy, 2002; 20 people: Stevens et al., 2004; three people: Lambeth Social Services, 2005). However, at a national level the Prime Minister's Strategy Unit (2005) recently reported that transition to adulthood is a key area for future development, with a requirement for 'planning focused on the individual needs' of young people.

\section{Health facilitators}

The implementation guidance for Valuing people required that by the summer of 2003 'there should be clearly identified HFs for PWLD' (DH, 2001b). Hudson (2003) saw a role for the proposed HF within transition planning, but was uncertain who would be responsible for this. Additional guidance (DH, 2002) saw the HF role operating at two levels: 'service development work' and 'person to person work'. To connect these two functions in tackling health inequalities Caan (2003) proposed a theoretical model of health facilitation based on developing 'linking social capital' for PWLD. Linking social capital helps open the doors of institutions and agencies that had previously seemed impossibly remote and inaccessible (Helliwell and Putnam, 2004).

\section{The context for developments in Barking and Dagenham}

The Barking and Dagenham partnership benefited from earlier work scoping the needs of local people and the service provision for learning disabilities (Messent, 2003). During 2003 they appointed two HFs. In October 2003, APU began an evaluation of their work over an initial period of six months. Previously, only limited literature on developments in this area was available (e.g., Corbett et al.,2003; Goodare,2003; Munyaradzi, 2003; Rodgers and Russ, 2003).

This paper will focus on just one of the initial HF posts, in accordance with the sponsors' changed priorities. A major responsibility for this post was improving the quality of transition plans for school leavers about to move to adult services.

\section{Method}

In July 2003, one member of the evaluation team met with the neighbourhood renewal unit to discuss their objectives for learning disabilities. Another member attended the national network for learning disability nurses conference which included the valuing people support team session on into the mainstream. The parameters of this evaluation were derived from these meetings (and the earlier literature search) and discussed with key stakeholders in Barking and Dagenham.

Nine developmental aspects of the new HF post were identified:

- Preparation

- Training needs during implementation

- Training delivered to others

- Baseline capacity and current provision

- Access to specific services in primary and community care

- Referrals to secondary care

- New capacity and capability

- Progress and barriers to progress

- Growing partnerships.

To investigate each of the dimensions, above, distinct methods were required. The mix of methods included:

- interviews with the new staff;

- shadowing HFs as they introduced their role to services;

- reflective diaries of HF activity;

- serial face-to-face questionnaires for key practitioners in the community;

- and focus groups for key managers in the area where the new HF role was implemented. 
The sponsors of the evaluation chose a learningin-action approach. Therefore preliminary findings were fed back and reviewed throughout the project. Altogether, quantitative and qualitative, subjective and objective observations were gathered by the team.

Initial contact was made with the HF by the APU team, to familiarize her with the evaluation and to elicit her personal aspirations and strengths. This included her past experience that might be preparation for this role. The HF was then shadowed in her practice. The HF was guided in preparing a reflective $\log$ (i.e., a diary) for four months of her contacts with both professionals and service users. The log also identified in-service training needs for herself and others. Both the log and shadowing informed our description of training delivered by the HF and helped to design a questionnaire for those professionals she contacted regularly. We also invited her to demonstrate any training materials or feedback from participants that they considered valuable to this role. The HF spontaneously added her own notes and commentaries on some of these documents.

We designed a questionnaire about service provision and access, to be used as an interview schedule during visits by the HF to other community professionals. An SPSS computer database was designed in parallel to the questionnaire to facilitate later statistical analysis of the answers using within-group before-and-after tests. Using roleplay, all three APU participants trained the HF in conducting this interview in a standardized way. Agreement was sought to follow up a purposive sample of diverse primary health care practitioners, with whom the HF had been in frequent contact. Five practitioners (from the wider population described in Table 1) consented to be interviewed through the winter of 2003-2004. The interview combined questions about the HF role with a search for concrete examples of recent LD contacts and the outcomes of these episodes of care. For adolescent service users approaching the transition to adult services, we especially sought examples of:

- involving young PWLD and their carers, in decisions about their care

- changes in professional partnerships that address newly recognized health needs.

Over time, this interview was repeated (up to) two more times, to observe any overall increase in service capacity.
Patterns of referrals (including improved access to services), growth of capacity across health systems and progress made were all discussed in two focus groups facilitated by two of the authors. One group involved primary care managers and the other involved managers in learning disability services. Approaches were made to all 21 individual managers of local agencies. Those chosen reflected the diverse services with which the HF interacted. Whereas all the practitioners who were approached participated in the interviews, only seven of the managers who had been approached actually attended their group. The main reasons for nonattendance were sickness or other absence from work. Participants' backgrounds ranged from specialist disability professionals within social work, community nursing and the voluntary sector, to primary care professions such as school nursing or health visiting. The Topic Guide designed for the focus groups centred on two of the nine developmental aspects (above) referrals and new capacity, and culminated in recommendations for future development across the local Partnerships.

The analysis of both the diaries and the transcripts of the focus groups centred upon sentinel content related a priori to the nine developmental areas, above. To interpret the key diary entries required prolonged immersion in all the texts. Provisional selection and crosschecking of related entries and concurrent validation of significant events with the diarist was required. However, analysis of the total content of all text collated was not judged appropriate for these initial months' work, as it was felt that the HF's literary language, detail and emphasis changed rapidly with experience. An external advisor from Homerton College was able to critically review the analysis conducted by APU.

\section{Flowchart of the sequence of activities undertaken by the evaluation team}

In 2003 the evaluation team:

- met the Barking and Dagenham planning team to decide a specification

- discussed the evaluation with stakeholders including the two HFs

- gathered literature, met with NRF team about social exclusion and access and discussed with trail-blazers from other areas 
- met with the HF about her previous experience and began her reflective diary

- designed the interview schedule and trained the HF

- developed the database for interviews

- chose topic guide issues and identified appropriate people for the focus groups

- shadowed the HF

- reviewed progress, with the planning team.

In 2004 the evaluation team:

- held Focus Groups

- collated data from the questionnaires and tapes

- examined the diary

- developed a database for contacts logged in the diary

- elicited feedback from the HF including additional notes and documents

- reviewed key findings with external reader, Homerton College

- agreed provisional content of the report for the Barking and Dagenham sponsors.

\section{Findings}

Findings are presented in relation to the developmental aspects of the new post.

\section{Preparation for this role and training needs}

The HF came from a clinical, nursing background that included experience of clients with learning disabilities in both residential and community services. She had also worked as a school nurse. She produced, unprompted, a mapping of her professional and educational development. This included some past work in this North East sector of London. The HF undertook quite a lot of Continuing Professional Development during her orientation to the novel post, and arranged a valued, external source of clinical supervision. As her skill and confidence grew, there were more diary entries recording her satisfaction with this job.

All the material from the interviews, the diary entries and the materials developed in this role (e.g., around epilepsy care) emphasized the primary health care dimension of the HF role. It appeared unlikely that a background such as social work or youth work would prepare someone sufficiently for the clinical and public health demands of this role.
Table 1 The main professional contacts recorded

\begin{tabular}{llc}
\hline Area & Type/Professional & $\begin{array}{c}\text { No. of } \\
\text { contacts }\end{array}$ \\
& & 16 \\
Health & School nurse & 9 \\
& Community LD nurse & 8 \\
& Nursing student & 6 \\
& Another HF & 4 \\
& Doctor & 3 \\
& Medical student & 3 \\
Social services & Allied health professional & 2 \\
Education & Specialist nurse & 11 \\
& Social worker & 7 \\
& Teachers & 2 \\
& Connexions & 1 \\
& Ofsted inspector & 1 \\
& School governor & 1 \\
Voluntary sector & Swimming instructor & 11 \\
Service users & Volunteers & 5 \\
& Patient and parents & 5 \\
& Patient alone & 2 \\
\hline & Parent alone &
\end{tabular}

Subsequent discussions in the focus groups confirmed the need for a clinical background, although not necessarily experience as a community learning disability nurse (CLDN). Other types of nurse, health visitors or allied health professionals with sufficient experience of learning disabilities 'on the job' might fulfil this role.

\section{Preparatory work with other professionals}

In less than four months (including the Christmas holiday period) the diary listed contacts with 150 individuals. This figure of 150 excludes additional group activities that were also recorded. The diary described 84 new contacts with individuals and 51 follow-up contacts. Table 1 shows the main types of contact, in the community. The HF also met with at least 27 groups, and gave telephone advice on at least six occasions. She also made a Radio broadcast and met the new Minister for Children (Margaret Hodge, Department for Education and Skills).

In addition to meeting the Partnership Board members, her own line managers and the APU team, the HF contacted 14 individuals with management roles at locality, PCT or Department of Health levels.

Every month of the diary was analysed separately to look for changes over time. Naturally, with time more of the contacts became follow-up 
meetings. In addition, there were three possible developments (although the numbers per month are too small for valid statistical tests). No 'person to person' work with parents or patients took place in the first month, but this direct client care built up from the second month onwards. In the final, fourth month, the two most common contacts became Volunteers and CLDNs - this may represent a deliberate strengthening of the HF linkages between primary care (such as School Nurses and Therapists) with specialist LD expertise in the community.

\section{Training delivered to others}

In interpreting these findings, animated discussion took place about the unexpected student teaching undertaken (see Table 1). On reflection, this training activity was considered appropriate to the development of the new role, and brought benefits. For example, training built links with a Consultant Paediatrician and his specialist service. Shadowing confirmed the value of this training activity. Topics included epilepsy awareness training for school nurses, and transition planning at a school for young people with special needs.

\section{Capacity of practice}

\section{Primary care at baseline}

The analysis of 13 interviews, with five informants, gave a much clearer picture of existing practice than of changes over time (because of missing or unclear responses in some of the follow-up sessions). For example, in health assessments described for eight young people, 33 professionals were involved, including: one general practitioner, five primary care trust nurses, five social service or education staff, two allied health professionals, one advocate and six staff from Specialist Services. Only four families were 'fully' involved in these health assessments.

From all this activity for the eight young people, in the absence of the HF, only one child obtained one additional service.

This pattern was confirmed by the HF in her diary, in relation to a young girl's health assessment she had begun:

- 'Mum's concerns are around adult provision and the lack of meaningful resources.'
In the focus groups the participants used phrases such as:

- 'quite a wide gap',

- 'a bit patchy',

- 'often people fall through the net',

- 'there wasn't much liaison with the GPs',

- 'we do not provide an actual service'.

\section{Secondary care at baseline}

Secondary care was also uneven in provision. The baseline interviews described five referrals to secondary care that produced a total of one service for one child.

\section{Access practitioner}

All five interviewees contacted the HF for help with access to health care. Her diary gives a characteristic entry, about using the opportunity of a first visit to a child development clinic: 'I actually assisted in many of the clinics ... as I had a lot of knowledge about some of the children'.

Two focus group participants confirmed that the HF's 'work was to look at the assessment process, and looking at issues prior to children coming into our service' and 'it is championing people with disabilities more'.

The way the HF undertook person to person work is characterized by this diary entry: 'I did my first home visit and it went very well, the mother really opened up to me about the needs of her child. It's a real pleasure to be able to offer some support and offer some help.'

She spent more of her time on service development work. In one focus group this was described: 'it was the quality of the service provided that had changed. It wasn't such a sparse service ... the parents ... knew where their services were, they had a named route into that service ... they knew exactly where they were going, and that was good, so wonderful for the families.'

The activity used to improve access was described at another point in that focus group as 'forward thinking'.

In general, access to services was improved for those service users who were already known to services. For the first few months of the new post, there were no accounts of new patients previously unknown to Barking and Dagenham services accessing care because of the HF. However, by the beginning of the fourth month the diary reported a new 
type of activity. This entry reflects an interagency meeting:

I was able to fill in many gaps with very important bits of information. ... I was even able to add children's names onto the list of children being discussed whom Social Services had no knowledge of. I really felt that this was a good example of health facilitation and the contribution/enhancement the role makes to the client group.

Independently, in a focus group a fortnight later, one manager relayed the news from her school nursing team: the $\mathrm{HF}^{\text {'has }}$ been the best thing that ever happened to their service, and she has filled the gaps that they could not fill themselves.'

\section{Referral systems}

Prior to health facilitation, the focus groups identified a number of problems around referrals between primary and secondary care, for example 'the physical disabilities were not properly integrated with primary care...'. Problems were described for epilepsy, difficult behaviours and complex conditions. A key concept from the focus groups was the added value of the HF in 'signposting'.

Transition planning before leaving school was a gap in local provision described by Messent (2003). The HF in her diary described 10 diverse contacts around transition plans. Additional areas where she undertook local improvements included mental health and epilepsy care.

\section{New capacity}

The follow-up interviews were too few and too incomplete to measure statistically significant changes. Two areas showed promise of new capacity, based on the diary and the documents and notes that the HF collected. First, interprofessional working had developed. For example, the $\log$ of an induction meeting for a new CLDN ends with the "main outcome was that we would have regular mini transition meetings to keep up-to-date on the progress of the various agencies involved'. Secondly, in the final month of the diary, voluntary agencies became increasingly involved. For example, after taping some joint training with a voluntary sector colleague, the HF noted:

It also gives me a good insight into how Person Centred Planning and Health Action
Plans can complement each other rather than be done in isolation.

\section{Progress, barriers and growing partnerships}

The networking and signposting service engaged with a remarkably wide variety of people. Many of the focus group contributions mentioned links, in accordance with our initial model about growing, 'linking social capital'. As the evaluation team reported findings to the sponsors, they reaffirmed a recommendation from the focus groups. To make HF linkages effective required this direct access, primary care resource to relate consistently to specialist learning disability staff including CLDNs. This was beginning to develop towards the end of this evaluation period. Barriers to transition planning were considered. It was suggested that the HF for adults should meet with the School-based HF and the Connexions service when the children reached 14.

\section{Other developmental issues that arose}

At all stages of this evaluation, there was discussion of the appropriate management arrangements and clinical supervision for these new post holders. In one focus group the participants felt that this was a job for an autonomous consultant nurse. There were also concerns about one person providing too wide a service, for example, across all age groups. They recognized the challenge of the HF working across all professional and nonprofessional boundaries, at user level and at strategic planning level. No one recommended that the HF should carry a caseload. Rather, they should be able to attend as a 'consultant' to support health professionals already involved in an individual's care, as and when required.

\section{Overview of the whole project}

At no time was there any observation that harm resulted from the introduction of the HF post. For example, there were no accounts at all of disruption or unwelcome interference with existing services.

\section{Discussion}

Across the UK, there is currently a gap in our understanding of the impact of health service developments, on PWLD (Cooper et al., 2004). 


\section{Limitations}

These are only preliminary observations, from one local authority and one primary care trust. Because of the large number of stakeholders and the complexity of the system into which HF was introduced, we chose a multimethod approach to evaluation. In general, comparing findings from different methods confirmed the same picture. The reflective $\log$ yielded richer material in greater volume than we anticipated, whereas the interview schedule was less productive than expected. Group discussions, especially the topic-driven focus groups, were highly informative. Shadowing practice and collating contemporary documents corroborated the other methods. Our experience with these methods in that community setting has now led to two further projects on health facilitation for adults and health action plans.

\section{Young people in transition and access to health care}

Incorporating advice from the neighbourhood renewal unit, the social exclusion unit has made young people's Transitions a national priority (ODPM, 2005). They recommend that young people need a trusted professional 'to help negotiate their way around different agencies', that is, to improve their linking social capital (Caan, 2003). Historically, the health service budget and programme planning for adults with learning disabilities has been in a separate silo from other health planning (Appleby, 2005). Fundamental to this HF innovation was the desire for a partnership joining different agencies. Although the HF drew on her community nursing experience with PWLD, her negotiating and collaborating efforts for young people in transition were more highly developed than would be the norm for CLDNs.

\section{Health facilitation in the future}

A review of the preliminary findings with the sponsors identified a gap in the infrastructure for this facilitating role. In order to prioritise the needs of future service users, a shared central record of their care should be established. This would also support future measures of health impact, in terms of addressing the significant, common health needs in this population. Valuing people (DH, 2001a) did not identify the skills and experience needed for the HF role. The person undertaking this pioneering role in our study had extensive experience both around learning disabilities and young people's health and education. With her additional, new experiences, she has subsequently helped to induct or mentor a growing cascade of HFs in other London Boroughs. The HF function has in every new case proved a demanding post to fulfil, with adults as well as children. Provision needs continuity across early years, primary school, secondary school and adult primary care/secondary care - this may require several highly skilled professionals.

It was advantageous to have direct access for parents and carers. HF needs to facilitate user-led development of services, next. Future developments should specify close partnership with CLDNs and other specialist services, while retaining a healthcare focus on the access to primary care.

Further developments should take account of the recent policy context. This includes department of health guidance on person-centred planning (Cole and Lloyd, 2005) and competence and responsibility within the Agenda for Change job evaluation scheme (DH, 2004b). We look forward to these issues being addressed by the new office for disability issues (Prime Minister's Strategy Unit, 2005).

\section{Conclusions}

Over time, this new role demonstrated engagement at both individual and service levels, with clear improvements in access for some existing service clients and the possibility of widening access. The focus groups were entirely positive about the added value for other services of introducing the HF role. For young people and their families, the HF could fulfil the concept of a vital friend (ODPM, 2005; Prime Minister's Strategy Unit, 2005). For professionals, the signposting and linking functions were new and creative, within the local health economy. These functions foreshadow the 'Lead Professional' role recently proposed to develop 'integrated front-line services' for Every Child Matters (DfES, 2005).

The service is likely to support social inclusion. This evolving system would provide support for parents and teachers and allow PWLD to be included as full citizens within the community.

In the longterm, health facilitation could benefit the wider health economy by:

1) being efficient, because the right people would see the right service at the right time 
2) giving potential for health promotion (Wanless agenda)

3) allowing managers to audit their service in relation to well specified needs and targets.

There has already been a noticeable impact on quality of care, therefore HFs have value in initiating change.

\section{Acknowledgement}

This evaluation was made possible by the enthusiastic co-operation of postholder Rena Williams throughout the project. Paul Valoo (London Borough of Barking and Dagenham) and Peter Messent (Barking and Dagenham Primary Care Trust) first enabled this evaluation to take place and then encouraged and supported the unfolding process.

\section{References}

Appleby, J. 2005: Where should all the money go? Health Service Journal 24, 23.

Beresford, B. 2004: On the road to nowhere? Young disabled people and transition. Child: Care, Health and Development 30, 581-87.

Caan, W. 2003: PCTs strike up the band for health facilitators. Health Service Journal 3, 23.

Cameron, L. and Murphy, J. 2002: Enabling young people with a learning disability to make choices at a time of transition. British Journal of Learning Disabilities 30,105-12.

Cole, A. and Lloyd, A. 2005: Shaping the future together. Foundation Stones 9, 2.

Commission for Social Care Inspection. 2004: Valuing people much achieved, more to do. London: Commission for Social Care Inspection.

Cooper, S.A., Melville, C. and Morrison, J. 2004: People with intellectual disabilities: their health needs differ and need to be recognised and met. British Medical Journal 329, 414-15.

Corbett, J., Thomas, C., Prior, M. and Robson, R. 2003: Health facilitation for people with learning disabilties. British Journal of Community Nursing 8, 404-10.

Department of Education and Skills. 2005: Lead professional good practice guidance. Consultation document. London: Department for Education and Skills.

Department of Health. 2001a: Valuing people: a new strategy for learning disability for the 21st century. London: Department of Health.

Department of Health. 2001b: Valuing people: a new strategy for learning disability for the 21st century: implementation. HSC 2001/016.
Department of Health. 2002: Action for health - health action plans and health facilitation. London: Department of Health.

Department of Health. 2004a: National service framework for children, young people and maternity services: standard 8: disabled children and young people and those with complex health needs. London: Department of Health and Department for Education and Skills.

Department of Health. 2004b: NHS job evaluation handbook, second edition. London: Department of Health.

Goodare, L. 2003: A new strategy for learning disability care. Nursing Times 99, 42-43.

Helliwell, J.F. and Putnam, R.D. 2004: The social context of well-being. Philosophical Transactions of the Royal Society (Biological Sciences) 359, 1435-46.

Hudson, B. 2003: From adolescence to young adulthood: the partnership challenge for learning disability services in England. Disability \& Society 18,259-76.

Lambeth Social Services. 2005: Valuing people. Person-centred planning in transition. Workshop in Community Care Live Children \& Families conference Event Guide, 27, 6-7.

Matthews, D., Fidler, D. and Thompson, L. 2002: A cause for concern. Learning Disability Practice 5, 10-12.

McMillan, I. 2004: Sue Culling, the recently installed nursing advisor at the department of health, tells Ian McMillan how she is settling into her new role. Learning Disability Practice 7,11 .

Messent, P.R. 2003: An evaluation of community learning disability nurse teams in two London boroughs. British Journal of Community Nursing 8, 411-20.

Munyaradzi, M. 2003: How do you see the role of the health facilitator developing with people with a learning disability in the community. Course presentation 9 June.

NHS Health Scotland. 2004: People with learning disabilities in Scotland. Glasgow: National Health Service Health Scotland.

NPSA. 2004: Understanding the patient safety issues for people with learning disabilities. www.npsa.nhs.uk/. Retrieved August 2005.

ODPM. 2005: Transitions. a social exclusion unit interim report on young adults. London: Office of the Deputy Prime Minister.

Prime Minister's Strategy Unit. 2005: Improving the life chances of disabled people. London: Cabinet Office.

Rodgers, J. and Russ, L. 2003: Better health for people with learning disabilities. Primary Health Care 13, 35-36.

SCIE Commission. 2003: Information review: structuring electronic access to knowledge about transition for young people with learning disabilities and their families and supporters. London: Social Care Institute for Excellence.

Social Exclusion Unit. 2001: A new commitment to neighbourhood renewal: national strategy action plan. London: Social Exclusion Unit.

Stevens, A., Toocaram, J. and Lutchmiah, J. 2004: circles of support - through transition. Final evaluation. Chelmsford: APU Centre for Research in Health and Social Care.

Trueland, J. 2004: Instead of looking at my disability, listen to what I'm trying to tell you. Health Service Journal 9, 14-15. 